\title{
Correction to: Can Cytokine Blocking Prevent Depression in COVID-19 Survivors?
}

\author{
Francesco Benedetti ${ }^{1,2}$ (1D - Mario Gennaro Mazza ${ }^{1,2} \cdot$ Giulio Cavalli $^{2,3} \cdot$ Fabio Ciceri $^{2,4} \cdot$ Lorenzo Dagna $^{2,3}$. \\ Patrizia Rovere-Querini ${ }^{2,4}$
}

Published online: 4 January 2021

(C) Springer Science+Business Media, LLC, part of Springer Nature 2020

\section{Correction to: Journal of Neuroimmune Pharmacology. https://doi.org/10.1007/s11481-020-09966-Z}

The original version of this article unfortunately contained a mistake. The author name "Mario Mazza" was incorrect.

Publisher's Note Springer Nature remains neutral with regard to jurisdictional claims in published maps and institutional affiliations.

The online version of the original article can be found at https://doi.org/ 10.1007/s11481-020-09966-Z

Francesco Benedetti

benedetti.francesco@hsr.it

1 Psychiatry \& Clinical Psychobiology, Division of Neuroscience, IRCCS Scientific Institute Ospedale San Raffaele, Milano, Italy

2 University Vita-Salute San Raffaele, Milano, Italy

3 Unit of Immunology, Rheumatology, Allergy, and Rare Diseases, IRCCS Scientific Institute Ospedale San Raffaele, Milano, Italy

4 Department of Medicine, Division of Immunology, Transplantation and Infectious Diseases, IRCCS Scientific Institute Ospedale San Raffaele, Milano, Italy 